\title{
Optimasi Time Dial Setting (TDS) Relay Arus Lebih Menggunakan Adaptive Modified Firefly Algorithm Pada Sistem Kelistrikan PT. Pupuk Kalimantan Timur
}

\author{
Vincentius Raki Mahindhara, Margo Pujiantara, Ardyono Priyadi \\ Jurusan Teknik Elektro, Fakultas Teknologi Industri, Institut Teknologi Sepuluh Nopember (ITS) \\ Jl. Arief Rahman Hakim, Surabaya 60111 Indonesia \\ e-mail: margo@ee.its.ac.id
}

\begin{abstract}
Abstrak-Penggunaan relay arus lebih (over current relay) pada industri memerlukan pengaturan beberapa parameter seperti arus pickup $\left(\mathrm{I}_{\mathrm{p}}\right)$, time dial setting (TDS), serta waktu operasi $\left(t_{o p}\right)$. Dalam standard acuan dicantumkan batasanbatasan dan formulasi dalam menentukan parameter tersebut. Salah satu permasalahan adalah penentuan TDS pada relay inverse (Kode ANSI 51). Umumnya penentuan nilai TDS dilakukan dengan metode trial and error, hal ini dirasa kurang efektif sehingga diusulkan suatu metode baru dalam menentukan TDS pada sistem kelistrikan eksisting PT. Pupuk Kalimantan Timur. Digunakan algoritma adaptive firefly yang dimodifikasi dalam menyelesaikan permasalahan dengan mempertimbangkan kurva starting motor dan perbedaan tipe kurva antar relay.
\end{abstract}

Kata Kunci-Firefly Algorithm, Koordinasi Proteksi, Overcurrent Relay

\section{PENDAHULUAN}

$\mathrm{P}$ enggunaan energi listrik dibidang industri selalu mengalami peningkatan seiring dengan pengembangan yang dilakukan. Kondisi tersebut tentu harus diikuti dengan perkembangan sistem proteksi kelistrikan, mengingat kemungkinan terjadinya gangguan listrik semakin tinggi. Pengembangan sistem proteksi kelistrikan dilakukan tidak hanya sekedar menggunakan peralatan yang handal, namun juga cara menentukan setting parameter pengamanan secara tepat. Hal ini bertujuan untuk mengamankan beban secara selektif dan akurat saat terjadi gangguan.

Salah satu peralatan yang digunakan pada sistem proteksi adalah relay arus lebih (overcurrent relay). Relay arus lebih bekerja untuk merasakan arus yang mengalir dan mengirimkan sinyal ke circuit breaker guna melindungi sistem dari kemungkinan gangguan hubung singkat (short circuit) atau beban lebih (overload). Parameter pengamanan arus hubung singkat dilakukan dengan waktu yang singkat (instantaneous time), sementara perlindungan beban lebih dengan waktu yang relatif lebih lama. Pada relay arus lebih, kedua kondisi ini digabungkan kedalam suatu kurva. Kondisi pengamanan tersebut dihubungkan melalui suatu karakteristrik dengan parameter yang harus diinputkan oleh operator ke dalam relay berupa arus pickup $\left(\mathrm{I}_{\mathrm{p}}\right)$, time dial setting (TDS), serta time delay $\left(\mathrm{t}_{\mathrm{d}}\right)$. Parameter tersebut harus ditentukan dengan mempertimbangkan arus yang mengalir pada beban, koordinasi antar relay, serta perlindungan terhadap beban esensial.

Penentuan parameter pada relay sejatinya telah diatur pada standar IEC 60255, IEEE 242, maupun BS 142. Pada standar tersebut dilakukan kalkulasi dengan menyediakan batasan minimum dan maksimum pada penentuan arus $\left(I_{P}\right)$ dan formulasi TDS. Akan tetapi pada implementasinya kerap terjadi kesalahan koordinasi karena sulitnya menentukan nilai TDS untuk beberapa relay dengan tipe kurva yang berbeda. Hal inilah yang menjadi permasalahan dan akan diselesaikan dalam tugas akhir ini.

Secara konvensional, penentuan TDS biasa dilakukan dengan metode trial and error. Pada metode tersebut, operator akan mencoba melakukan plotting karakteristik melalui kurva Time Current Characteristic (TCC). Dari kurva tersebut maka operator akan mengamati koordinasi antar relay dan menghindari kemungkinan relay trip secara bersamaan. Tentu saja metode ini memerlukan banyak perulangan (iterasi) dan membutuhkan waktu yang lama. Oleh karena itu diusulkan suatu metode optimasi menggunakan firefly algorithm. Algoritma ini merupakan suatu kecerdasan buatan yang terinsipirasi dari perilaku koloni kunang-kunang yang ditemukan peneliti Cambridge University, Xin-She Yang pada tahun 2008 [3].

PT. Pupuk Kalimantan Timur merupakan perusahaan yang bergerak dibidang industri kimia dengan mengolah gas alam menjadi pupuk. Sejak berdiri pada tahun 1977, pengembangan pabrik terus dilakukan hingga saat ini telah memiliki tujuh pembangkit listrik (Kaltim-1 14 MW (Off), Kaltim-2 28 MW, Kaltim-3 26 MW, Kaltim-4 20 MW, Kaltim-5-1 30 MW, Kaltim-5-2 30 MW, dan KDM 26 MW). Masing-masing pembangkit diintegrasikan melalui suatu ring bus pada tegangan $33 \mathrm{kV}$ untuk mensuplai daya listrik pada beban pabrik PT. Pupuk Kalimantan Timur (Kaltim-1, Kaltim-2, Kaltim-3, Kaltim-4, Kaltim-5, POPKA, dan fasilitas pendukung berupa mini substation untuk perkantoran dan perumahan) serta beban pada pabrik joint venture yang mengolah ammonia dari Pupuk Kaltim seperti PT. KPA, PT. KPI, PT. KDM, PT. KNI, PT. KMI. PT. OKM. 
Tabel I

Koefisien Kurva Inverse Standard Iec

\begin{tabular}{lccc}
\hline \hline \multicolumn{1}{c}{ Tipe Kurva } & $\boldsymbol{k}$ & $\boldsymbol{\alpha}$ & $\boldsymbol{\beta}$ \\
\hline Long Time Inverse & 120 & 1 & 13,33 \\
Standard Inverse & 0,14 & 0.02 & 2,97 \\
Very Inverse & 13,5 & 1 & 1.5 \\
Extremely Inverse & 80 & 2 & 0,808 \\
Ultra Inverse & 315,2 & 2.5 & 1 \\
\hline \hline
\end{tabular}

\section{PRINSIP KOORDINASI PROTEKSI}

Tujuan dari koordinasi proteksi sistem kelistrikan dengan parameter arus adalah untuk menentukan karateristik, rating, dan setting dari peralatan pengaman arus lebih yang berfungsi untuk meminimalisasi kerusakan perangkat serta melokalisir hubung singkat sesegera mungkin. Peralatan pengaman arus lebih bekerja dengan bagian primer dan backup. Bagian primer merupakan barisan pertama dalam menanggulangi kerusakan akibat gangguan. Tentu saja pada bagian primer, diperlukan peralatan yang bekerja lebih cepat dan apabila gagal akan ditanggulangi oleh peralatan backup.

Pada peralatan proteksi, pickup memiliki arti nilai minimum arus yang mengalir sebelum perangkat memulai tindakan. Dengan kata lain, logika berpikir yang digunakan dalam peralatan (dalam hal ini relay arus lebih) adalah sebagai berikut:

Jika $\mathrm{I}_{\mathrm{F}} \geq \mathrm{I}_{\mathrm{P}}$, maka relay mengirimkan sinyal trip

Jika $\mathrm{I}_{\mathrm{F}}<\mathrm{I}_{\mathrm{P}}$, maka relay tidak melakukan apa-apa

( $\mathrm{I}_{\mathrm{F}}$ adalah arus gangguan dan $\mathrm{I}_{\mathrm{P}}$ adalah arus pickup)

Menurut British Standard BS 142, batas dalam menentukan arus pickup pada relay sebagai pelindung dari beban lebih adalah:

\section{1,05 FLA $<\mathrm{I}_{\mathrm{P}}<1,4$ FLA}

Sementara untuk batas penentuan arus pickup pada relay sebagai pelindung kejadian hubung singkat adalah:

\section{1,6 FLA $<\mathrm{I}_{\mathrm{P}}<0,8 \mathrm{I}_{\mathrm{SC} \text { MIN }}$}

Dimana FLA adalah Full Load Ampere yang berarti arus yang mengalir pada beban sesuai daya maksimum dan ISC MIN $_{\text {M }}$ adalah arus hubung singkat minimum $\left(\mathrm{I}_{\mathrm{SC}} 2 \varnothing\right)$ dalam durasi steady state (30 cycle).

Suatu kurva TCC (Time Current Characteristic) mendefinisikan waktu operasi dan nilai arus operasi pada suatu peralatan proteksi. Kurva TCC digunakan sebagai panduan perancang dalam membuat suatu skema koordinasi proteksi. Kerangka pemikiran yang diperlukan adalah menentukan apakah antar kurva pada TCC boleh bersinggungan atau tidak, sesuai dengan kebutuhan koordinasi. Relay arus lebih pada umumnya digambarkan dalam suatu kurva satu garis. Pada relay inverse (Kode ANSI 51) terdapat beberapa tipe kurva yang membantu dalam melakukan koordinasi. Tipe kurva ini ditentukan berdasarkan persamaan berikut [2] (IEC Standard)

$t_{o p}=\frac{k x T D S}{\left(\left(\frac{I}{U_{P}}\right)^{\mathrm{x}}-1\right) x \beta}$

Dimana $\mathrm{t}_{\mathrm{op}}$ adalah waktu operasi relay, TDS adalah Time
Tabel II

Clearing Time Interval Relay

\begin{tabular}{lcc}
\hline \hline \multirow{2}{*}{ Kerja Relay } & \multicolumn{2}{c}{ Tipe Relay } \\
\cline { 2 - 3 } & $\begin{array}{c}\text { Electro } \\
\text { mechanical }\end{array}$ & Static \\
\hline Circuit breaker opening time & $0,08 \mathrm{~s}$ & $0,08 \mathrm{~s}$ \\
Relay overtravel & $0,10 \mathrm{~s}$ & $0,00 \mathrm{~s}$ \\
Relay tolerance and setting errors & $0,12 \mathrm{~s}$ & $0,12 \mathrm{~s}$ \\
\hline Total CTI & $0,30 \mathrm{~s}$ & $0,20 \mathrm{~s}$ \\
\hline \hline
\end{tabular}

Dial Setting, I adalah arus pada keadaan $\mathrm{t}_{\mathrm{op}}$ dan $\mathrm{I}_{\mathrm{P}}$ adalah arus pickup untuk perlindungan beban lebih. Persamaan (1) juga disusun dengan beberapa koefisien yang dilampirkan pada tabel 1 [2].

Salah satu pertimbangan dalam melakukan koordinasi relay arus lebih selain menentukan gradasi arus pickup adalah penentuan waktu kerja relay. Tanpa adanya interval antar relay, peralatan pengaman mungkin bekerja secara tidak tepat dan dapat memutus aliran daya ke lokasi yang tidak mengalami gangguan. Pada kurva arus dan waktu (TCC), selain memperhatikan koordinasi dengan tidak mentolerir adanya kurva relay yang berpotongan, perlu diperhatikan juga durasi tunggu antar relay. Dengan peralatan yang modern, durasi tunggu antar relay dipengaruhi oleh beberapa faktor seperti cara kerja relay, overtravel relay, dan toleransi error. Secara ringkas, batasan CTI dapat ditinjau pada tabel 2 [1].

\section{FIREFLY ALGORITHM}

Firefly algorithm [3] adalah suatu algoritma yang terinspirasi dari perilaku kunang-kunang pada alam bebas. Kunang-kunang yang tersebar memiliki posisi dan intensitas cahaya masing-masing. Pada algoritma ini, setiap kunangkunang dianggap unisex (semua kunang-kunang berjenis kelamin sama) dan ketertarikan kunang-kunang satu dengan lainnya dipengaruhi oleh intensitas cahayanya. Artinya, kunang-kunang yang lebih terang akan didekati oleh kunangkunang yang redup.

Dalam aplikasinya, intensitas kecerahan tiap kunangkunang dirumuskan melalui objective function persamaan yang akan diselesaikan. Semakin benar nilai pada kunang-kunang tersebut, maka semakin terang intensitas cahayanya. Selanjutnya, dilakukan pembaruan posisi kunang-kunang yang terpengaruh oleh intensitas cahaya kunang-kunang lain. Perubahan posisi kunang-kunang dirumuskan melalui persamaan berikut:

$x_{i}=x_{i}+\beta_{0} e^{-Y Y_{i j}^{2}}\left(x_{j}-x_{i}\right)+\alpha e$

Dimana $x$ adalah posisi kunang-kunang, $i$ adalah posisi kunang-kunang, $j$ adalah posisi kunang-kunang pembanding, $\beta$ adalah faktor ketertarikan kunang-kunang (attractiveness), $\gamma$ adalah faktor kemampuan penyerapan cahaya, $r$ adalah jarak antara kunang-kunang $i$ dan $j, \alpha$ adalah parameter acak (randomization) pergerakan kunang-kunang, dan $E$ adalah suatu vektor berisi konstanta acak yang mengacu pada Distribusi Gaussian.

Koefisien $\beta, \gamma$, dan $\alpha$ bernilai 0 sampai 1. Nilai ini $\beta$ yang semakin besar akan mempercepat kunang-kunang dalam mendekati kunang-kunang lain yang lebih terang namun 
dengan hasil yang tidak akurat. Sementara itu koefisien $\gamma$ dapat dimisalkan sebagai kondisi cuaca saat pergerakan kunang-kunang. Semakin besar nilai $\gamma$ berarti kondisi cuaca saat itu sedang berkabut yang mengakibatkan kunang-kunang tidak dapat melihat kunang-kunang yang lebih terang pada posisi yang lebih jauh. Koefisien $a$ berfungsi sebagai faktor pengali dari nilai vektor kunang-kunang. Semakin besar nilai $a$ berarti gerakan kunang-kunang akan semakin acak dan semakin kecil nilai $\alpha$ berarti gerakan kunang-kunang cenderung diam.

Untuk melakukan optimasi Time Dial Setting (TDS) pada sistem proteksi KALTIM-3 dan KALTIM-4, digunakan firefly algorithm dengan berbagai modifikasi untuk disesuaikan dengan permasalahan yang dihadapi. Algoritma firefly disusun sebagai berikut:

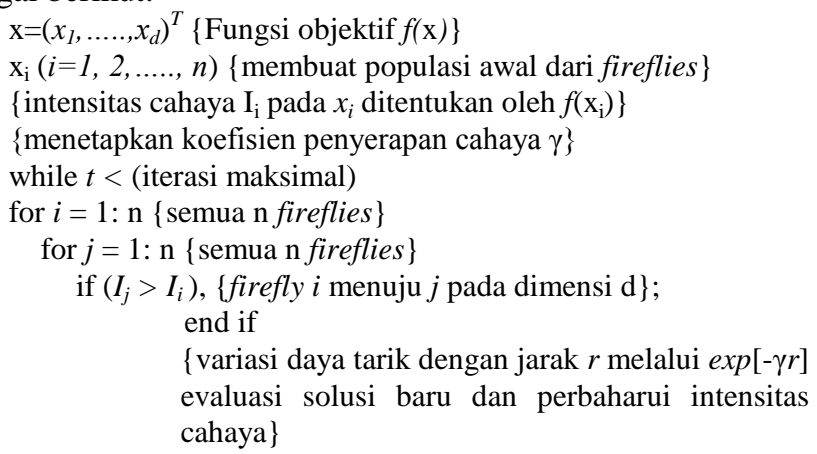

Fungsi objektif yang akan diselesaikan pada algoritma ini adalah fungsi waktu terhadap arus yang dapat dari persamaan (1). Lalu dilakukan inisiasi awal sebaran kunang-kunang yang merupakan nilai acak dari TDS pada posisi acak pula. Pemberian nilai acak TDS ini dilakukan dengan memperhitungkan batasan TDS yang dimiliki masing-masing Overcurrent Relay (OCR). Untuk mengetahui intensitas cahaya masing-masing kunang-kunang dilakukan pembandingan nilai objektif TDS terhadap waktu operasi $\left(\mathrm{t}_{\mathrm{op}}\right)$ yang telah ditentukan oleh perancang. Semakin besar selisih antara $t_{o p}$ dengan nilai objektif TDS, maka semakin redup intensitas cahaya kunang-kunang tersebut. Sebaliknya, semakin kecil selisih antara $t_{\text {op }}$ dengan nilai objektif TDS, maka semakin terang intensitas cahaya kunang-kunang tersebut. Setelah melakukan evaluasi tiap kunang-kunang, dijalankan fungsi algoritma untuk melakukan pembaruan posisi dan nilai masing-masing kunang-kunang dengan cara membandingkan intensitas cahaya kunang-kunang dengan kunang-kunang setelahnya pada satu populasi. Pada akhir iterasi, didapatkan nilai TDS dengan intensitas cahaya paling terang. Apabila nilai TDS tersebut dimasukkan kedalam fungsi objektif, maka akan didapatkan waktu operasi yang paling mendekati dengan target perancang.

Demi meningkatkan kemampuan algoritma dalam menyesuaikan nilai objektif dengan kondisi nyata, maka dipertimbangkan pula kondisi-kondisi dimana relay tidak boleh beroperasi atau mengirimkan sinyal trip. Maka dari itu, dilakukan pemodelan terhadap beban (khususnya motor

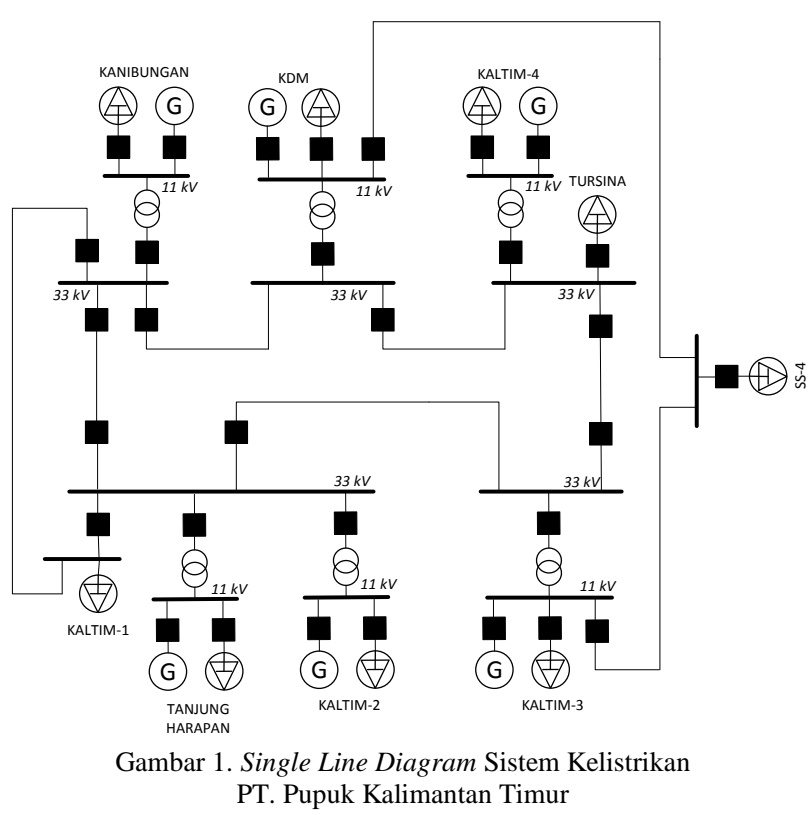

induksi) dan pertimbangan clearing time interval (CTI) dalam menentukan TDS. Apabila nilai TDS tidak memenuhi syarat perlindungan beban maupun CTI, maka input nilai $t_{\mathrm{op}}$ oleh perancang akan dievaluasi agar mendapatkan hasil yang lebih baik.

\section{PT. PUPUK KALIMANTAN TIMUR}

Secara umum, sistem kelistrikan PT. Pupuk Kalimantan Timur dibangkitkan oleh enam generator aktif yang tersebar dimasing-masing island. Pada masing-masing island level tegangan yang digunakan adalah $11 \mathrm{kV}$. Beban yang banyak digunakan adalah motor induksi dengan regulasi level tegangan diatur sesuai dengan rating motor tersebut. Apabila rating motor lebih besar dari 1,85 MW, maka wajib terhubung dengan bus $11 \mathrm{kV}$. Sementara motor dengan rating dibawah 1,85 MW dan diatas $220 \mathrm{~kW}$ wajib terhubung dengan bus 6,6 $\mathrm{kV}$.

Skema tipikal 1 merupakan koordinasi beban dengan feeder transformator terbesar pada pabrik KALTIM-3 (Lumped Load 53 sebesar 2,5 MVA) yang terhubung dengan bus 52-SG-101 $11 \mathrm{kV}$ dan Generator 16-Z-001. Gangguan terjadi pada beban (Lumped Load 53). Pemilihan skema ini bertujuan untuk memantau kemampuan optimasi TDS pada suatu relay dengan batasan kurva definite pada salah satu relay (pada tipikal ini Generator 16-Z-001 dilengkapi dengan OCR 51 dengan kurva definite). Pada skema tipikal 2, dilakukan koordinasi menyerupai tipikal 1 yaitu dari beban terbesar pada pabrik KALTIM-3 (Lumped Load 53 sebesar 2,5 MVA) yang terhubung dengan bus 52-SG-101 $11 \mathrm{kV}$, namun sistem terkoordinasi dengan sistem interkoneksi ring bus $33 \mathrm{kV}$. Gangguan terjadi pada beban (Lumped Load 53). Pertimbangan pemilihan tipikal ini adalah kedua relay yang akan dikoordinasi memiliki tipe kurva inverse. Pada skema koordinasi tipikal 3, dilakukan pengamanan pada beban motor induksi (12-PM-101B) Pabrik KALTIM-4 yang terhubung langsung dengan bus 00-SG-101 $11 \mathrm{kV}$ yang terkoneksi 


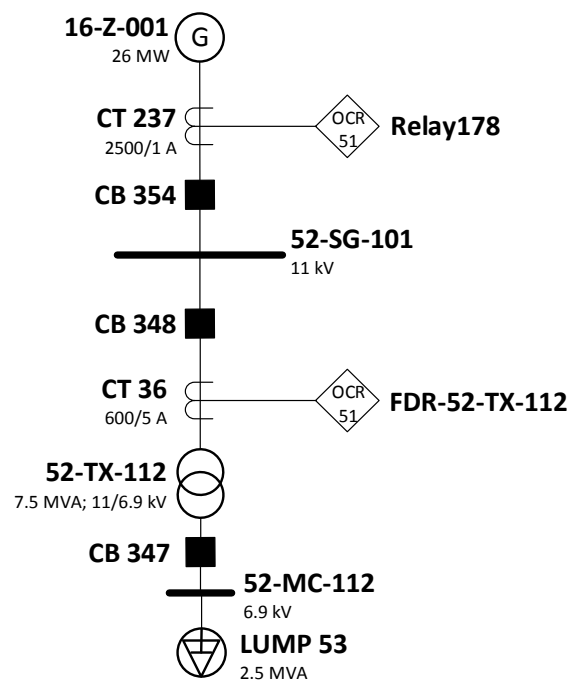

Gambar 2. Single Line Diagram Tipikal 1

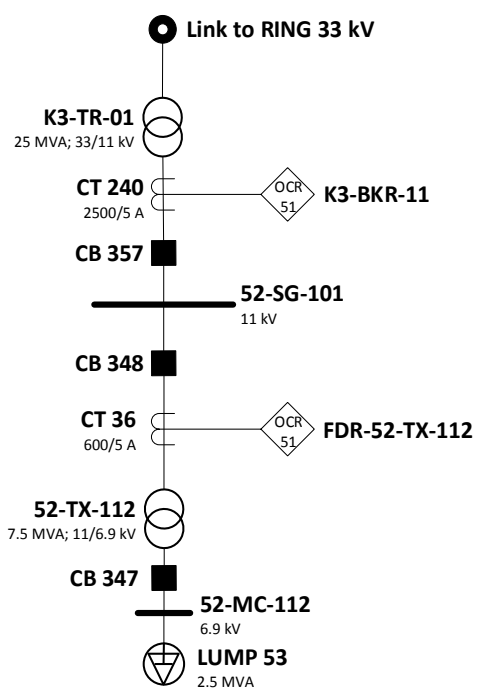

Gambar 3. Single Line Diagram Tipikal 2

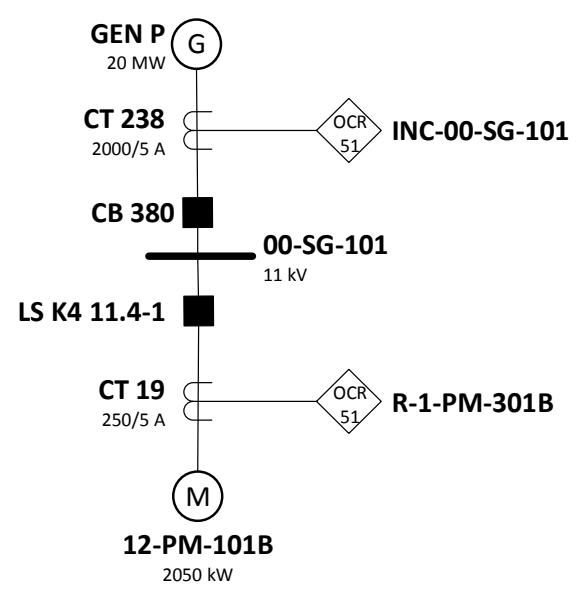

Gambar 4. Single Line Diagram Tipikal 3

Tabel III

Perbandingan Hasil Antar Metode Tipikal 1

\begin{tabular}{lcccccc}
\hline \hline & \multicolumn{2}{c}{ FDR-52-TX-112 } & \multicolumn{2}{c}{ Relay 178 } & \multicolumn{2}{c}{ CTI } \\
\hline & $\begin{array}{c}\text { Konven } \\
\text { sional }\end{array}$ & $\begin{array}{c}\text { Opti } \\
\text { masi }\end{array}$ & $\begin{array}{c}\text { Konven } \\
\text { Sional }\end{array}$ & $\begin{array}{c}\text { Opti } \\
\text { masi }\end{array}$ & $\begin{array}{c}\text { Konven } \\
\text { sional }\end{array}$ & $\begin{array}{c}\text { Opti } \\
\text { masi }\end{array}$ \\
\hline $\mathrm{TDS}$ & $0,11 \mathrm{~s}$ & $0,08 \mathrm{~s}$ & $0,5 \mathrm{~s}$ & $0,5 \mathrm{~s}$ & & \\
$\mathrm{t}_{\mathrm{d}}$ & $0,154 \mathrm{~s}$ & $0,112 \mathrm{~s}$ & $0,5 \mathrm{~s}$ & $0,5 \mathrm{~s}$ & & \\
$\Delta \mathrm{T}$ & & & & & $0,349 \mathrm{~s}$ & $0,39 \mathrm{~s}$ \\
\hline \hline
\end{tabular}

Tabel IV

Perbandingan Hasil Antar Metode Tipikal 2

\begin{tabular}{lcccccc}
\hline \hline & \multicolumn{2}{c}{ FDR-52-TX-112 } & \multicolumn{2}{c}{ Relay 178 } & \multicolumn{2}{c}{ CTI } \\
\hline & $\begin{array}{c}\text { Konven } \\
\text { sional }\end{array}$ & $\begin{array}{c}\text { Opti } \\
\text { masi }\end{array}$ & $\begin{array}{c}\text { Konven } \\
\text { sional }\end{array}$ & $\begin{array}{c}\text { Opti } \\
\text { masi }\end{array}$ & $\begin{array}{c}\text { Konven } \\
\text { sional }\end{array}$ & $\begin{array}{c}\text { Opti } \\
\text { masi }\end{array}$ \\
\hline $\mathrm{TDS}$ & $0,11 \mathrm{~s}$ & $0,08 \mathrm{~s}$ & $0,1 \mathrm{~s}$ & $0,1 \mathrm{~s}$ & & \\
$\mathrm{t}_{\mathrm{d}}$ & $0,154 \mathrm{~s}$ & $0,112 \mathrm{~s}$ & $0,656 \mathrm{~s}$ & $0,656 \mathrm{~s}$ & & \\
$\Delta \mathrm{T}$ & & & & & $0,41 \mathrm{~s}$ & $0,523 \mathrm{~s}$ \\
\hline \hline
\end{tabular}

Tabel V

Perbandingan Hasil Antar Metode Tipikal 3

\begin{tabular}{lcccccc}
\hline \hline & \multicolumn{2}{c}{ R-1-PM-301B } & \multicolumn{2}{c}{ INC-00-SG-101 } & \multicolumn{2}{c}{ CTI } \\
\hline & $\begin{array}{c}\text { Konven } \\
\text { sional }\end{array}$ & $\begin{array}{c}\text { Opti } \\
\text { masi }\end{array}$ & $\begin{array}{c}\text { Konven } \\
\text { sional }\end{array}$ & $\begin{array}{c}\text { Opti } \\
\text { masi }\end{array}$ & $\begin{array}{c}\text { Konven } \\
\text { sional }\end{array}$ & $\begin{array}{c}\text { Opti } \\
\text { masi }\end{array}$ \\
\hline $\mathrm{TDS}$ & $0,75 \mathrm{~s}$ & $0,61 \mathrm{~s}$ & $0,4 \mathrm{~s}$ & $0,4 \mathrm{~s}$ & & \\
$\mathrm{t}_{\mathrm{d}}$ & $0,15 \mathrm{~s}$ & $0,122 \mathrm{~s}$ & $0,508 \mathrm{~s}$ & $0,508 \mathrm{~s}$ & & \\
$\Delta \mathrm{T}$ & & & & & $0,382 \mathrm{~s}$ & $0,41 \mathrm{~s}$ \\
\hline \hline
\end{tabular}

dengan Generator GenP. Gangguan terjadi pada beban motor 12-PM-101B. Pemilihan tipikal ini bertujuan untuk menguji program optimasi TDS dalam mempertimbangkan kurva starting motor yang tidak terhubung dengan peralatan starting apapun (metode start berupa direct online) dan berada pada level tegangan yang sama dengan generator sehingga tidak terdapat transformator maupun impedansi lain yang dapat meredam arus starting.

\section{HASIL PENGUJIAN}

Setelah mendapatkan hasil dari metode konvensional dan metode optimasi menggunakan adaptive modified firefly algorithm, maka dapat dilakukan analisis dan perbandingan antar metode tersebut. Dari tabel III dapat dianalisis bahwa metode optimasi mampu meminimalisir waktu operasi pada relay FDR-52-TX-112 dari 0,154 detik menjadi 0,112 detik.
Sementara pada Relay 178 tidak dilakukan optimasi karena tipe kurva definite time. Hal ini memperbesar sela Clearing Time Interval (CTI) dari 0,349 detik menjadi 0,39 detik. Pengurangan waktu operasi ini menunjukkan bahwa metode optimasi TDS menggunakan firefly algorithm memiliki tingkat keakuratan lebih baik dibanding metode konvensional dalam menentukan TDS untuk mendekati nilai target waktu operasi.

Sementara itu tabel IV menunjukkan data perbandingan antara kedua metode untuk menentukan TDS pada tipikal 2. Dalam kasus ini, relay FDR-52-TX-112 sejatinya telah dioptimasi pada tipikal sebelumnya, namun keunikan dari tipikal ini adalah koordinasi dilakukan antara dua relay dengan kurva inverse (pada tipikal 1 koordinasi antara kurva inverse dan definite). Hasil optimasi TDS yang didapat pada relay FDR-52-TX-112 sama dengan hasil pada tipikal 1 sementara untuk relay $\mathrm{K} 3-\mathrm{BKR}-11$, tidak terdapat perbedaan hasil optimasi dengan metode konvensional. Hal ini disebabkan 
karena keterbatasan range TDS sehingga optimasi yang dilakukan gagal mencapai target waktu operasi yang diberikan. Pengurangan waktu operasi pada relay FDR-52-TX-112 memperbesar sela CTI antar relay menjadi 0,523 detik dari sebelumnya 0,41 detik.

Pada tabel V, ditunjukkan data dari kedua metode untuk melakukan optimasi pada koordinasi proteksi tipikal 3. Pada relay $\mathrm{R}-1-\mathrm{PM}-301 \mathrm{~B}$ dapat dianalisis bahwa metode optimasi TDS menggunakan firefly algorithm mampu mengurangi waktu operasi dari 0,15 detik menjadi 0,122 detik. Hal ini dikarenakan kemampuan algoritma untuk mereduksi nilai TDS dan melakukan evaluasi dengan lebih teliti dengan mempertimbangkan karakteristik beban. Pada tipikal ini, metode optimasi melakukan evaluasi terhadap target waktu operasi relay R-1-PM-301B dari 0,05 detik menjadi 0,1 detik, sehingga data yang diperlukan menjadi lebih akurat. Sementara itu untuk relay INC-00-SG-101, tidak ada perbedaan antara metode konvensional dan metode optimasi karena nilai waktu operasi aktual sudah memiliki error paling kecil (target waktu operasi adalah 0,5 detik). Sela waktu CTI antara kedua relay meningkat pada metode optimasi menjadi 0,41 detik dibanding metode konvensional sebesar 0,382 detik.

\section{KESIMPULAN}

Terdapat kekeliruan dan perlu dilakukan verifikasi pada relay FDR-52-TX-112 (lokasi Pabrik KALTIM-3) dengan mempertimbangkan koordinasi terhadap relay generator maupun relay outgoing ring $33 \mathrm{kV}$. Pada kasus ini, firefly algorithm yang telah dimodifikasi dapat mengerjakan optimasi dalam menentukan TDS dengan fungsi objektif berupa waktu operasi. Saran untuk penelitian selanjutnya adalah melakukan pengembangan untuk menambah kemampuan adaptasi dengan mengevaluasi tipe kurva maupun nilai arus pickup ketika fungsi objektif gagal dicapai. Selain itu perlu dilakukan penyesuaian dengan relay instantaneous (Kode ANSI 50) agar menambah keandalan relay dalam melakukan sensing.

\section{DAFTAR PUSTAKA}

[1] IEEE Standard 242, "Protection and Coordination of Industrial and Comercial Power System", Institut of Electrical and Elenctronics Engineers, 2001.

[2] Protection and Control, "Sepam 1000: Sepam Range Substations, Busbars, Transformers, Motors", Groupe Schneider. 1998

[3] Yang, Xin-She. "Nature-Inspired Metaheuristic Algorithms: Second Edition”. University of Cambridge: 2010. 